\title{
Vinte e quatro notas de viadagem
}

Leandro Soares da Silva ${ }^{1}$

Resumo: Estas notas são breves considerações sobre a questão da viadagem. Podem ser lidas como aforismos, argumentos para uma hipótese, notações para um artigo porvir, um artigo acadêmico em si (e um artigo quase acadêmico), uma tentativa deliberada de não pôr ordem no caos, uma provocação, um manifesto bastardo e um convite. Estas notas se propõem, se for esse o verbo correto, a pensar sobre a viadagem como uma ferramenta ambígua para a desarticulação de formas machistas de dominação.

Palavras-chave: Viadagem; Homossexualidade; Teoria Queer; Desconstrução.

Abstract: These notes are short considerations on viadagem. They may be read as aphorisms, arguments for a hypothesis, topics for a future paper, an academic paper itself (and a quasi-academic paper), a deliberate attempt to not order chaos, a defiance, a bastard manifest, and an invitation. These notes propose (if that verb is correct) to think viadagem as an ambiguous appliance to disarticulate sexist forms of domination.

Keywords: Viadagem; Homosexuality; Queer Theory; Deconstruction

Resumen: Estas notas son consideraciones breves sobre viadagem. Pueden leerse como aforismos, argumentos a favor de una hipótesis, temas para un artículo futuro, un trabajo académico en sí (y un trabajo cuasi académico), un intento deliberado de no ordenar el caos, un desafío, un manifiesto bastardo, y una invitación. Estas notas se proponen (si ese verbo es correcto) a pensar viadagem como dispositivo ambiguo para desarticular las formas de dominación sexista.

Palabras-clave: Viadagem; Homosexualidad; Teoría Queer; Deconstrucción

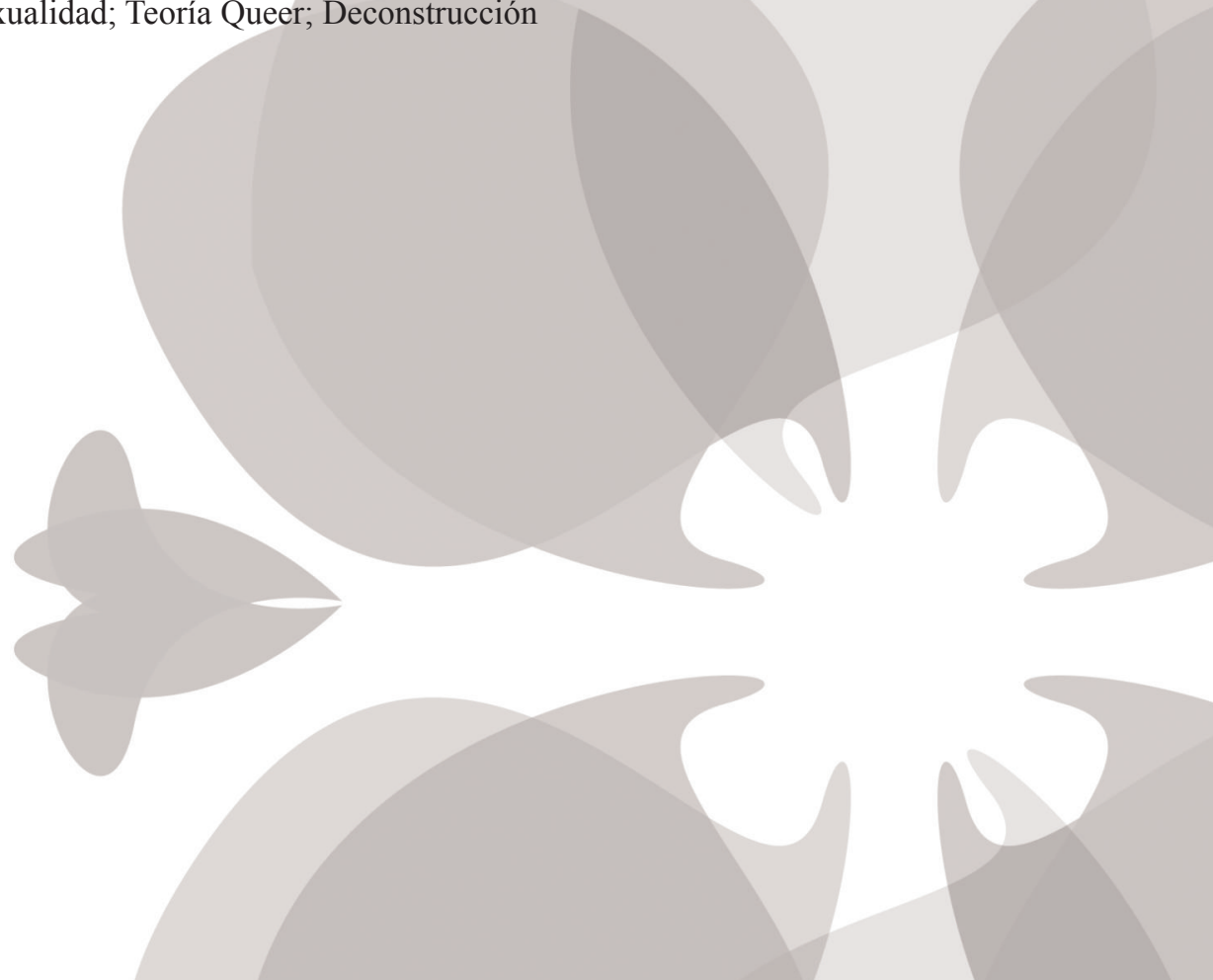

1 Professor de Literatura na Universidade do Estado da Bahia. Doutorando em Teoria Literária e Literatura Comparada na Universidade Federal de Minas Gerais. 
1. De todas as coisas nomeadas, algumas têm mais nomes do que outras. Por exemplo, o insulto. Quando um nome é insulto, ele performa sobre os corpos envolvidos os afetos correspondentes, mas não abandona todos os outros nomes além do nome de injúria. Putas, travecos, rachas, nigrinhas, sapatas \& viados cada um e todos juntos possuem uma história.

2. Um nome nunca é menos do que um nome. Primeiro, o ato de nomear, a falsa origem de tudo. Falsa por não haver origem, mas citação. Toda linguagem é citação e citacional é o gênero: os limites dos nossos corpos são discursivos. E os discursos agem materialmente sobre os corpos. Um exemplo radical: de todos os atos violentos que o corpo masculino pode sofrer, estupro é o último a ser considerado. O corpo masculino é inviolável. As mulheres, por outro lado, vivem sob o risco do estupro, são até acusadas de provocar o criminoso, porque a materialidade do corpo da mulher vive sob um regime de controle diferente do homem. Não se fala, problematiza, escreve, divulga, constrói a ideia de homem estuprado. Seu corpo está além da objetificação. Mesmo assim, nós sabemos que homens violados sempre existiram. Nunca existiu a noção de que os corpos masculinos são mais fáceis, mais excitantes, mais provocadores(irrecusavelmente provocadores), mais disponíveis, mais frágeis e vulneráveis. Um nome extrai do corpo uma ação, um afeto, uma afeção

3. Viadagem é uma palavra bastarda. Todo apreço pelo bastardo, esse descendente que carrega para a posteridade a diferença como princípio. O outro, o impuro, o ilegítimo, o nãonatural dividem conosco a sabedoria da origem imaculada como mito. Lá onde querem origem, diz o bastardo, só há violência e repressão.
Uma pessoa não é apenas determinada pelo nome que é chamada. Ao ser chamada por um nome de insulto, uma pessoa é humilhada e menosprezada. Mas o nome contém outra possibilidade também: ao ser insultada, à pessoa é dada, paradoxalmente, uma certa possibilidade para a existência social, iniciada na vida temporal da linguagem que excede o objetivo prévio que anima o insulto. Assim, a injúria pode aparecer para fixar ou paralisar, mas também produz uma inesperada e capacitada resposta. Ser chamado é ser interpelado, logo o insulto corre o risco de inaugurar um sujeito no discurso que usa a língua para reagir à ofensa. (BUTLER, 1997, p. 2).

Todo signo, linguístico ou não-linguístico, falado ou escrito (no sentido corrente dessa oposição), em pequena ou grande escala, pode ser citado, posto entre aspas; por isso ele pode romper com todo contexto dado, engendrar ao infinito novos contextos, de modo absolutamente nãosaturável. (DERRIDA, 1991a, p. 25).

O gênero é a estilização repetida do corpo, um conjunto de atos repetidos no interior de uma estrutura reguladora altamente rígida, a qual se cristaliza no tempo para produzir a aparência de uma substância, de uma classe natural de ser. (BUTLER, 2010, p. 59).

Podemos investigar o retorno à matéria como anterior ao discurso para sustentar nossas afirmações sobre a diferença sexual apenas para descobrir que a matéria é totalmente sedimentada em discursos sobre sexo e sexualidade que prefiguram e restringem os usos nos quais o termo pode ser utilizado. (BUTLER, 1993, p. 5). 
4. Viadagem é ilegítima. Vem do menos legítimo ainda viado. Viado é a pronúncia brasileira do nome do cervo, o veado. Viado tem essa origem, um meneio de pronúncia dessa língua toda própria, des-viada, o português do Brasil. E da pronúncia errada vem o insulto. Viado hoje é ampla e reconhecidamente admitido como injúria a homens gays; veado continua a ser o bicho. Só se sabe a diferença entre um e outro procurando pelo contexto; ou na escrita.

5. A grande vereda da différance: o desvio ortográfico marca uma outra palavra, bastarda em relação ao vocábulo original, que diferencia dois tipos de bichos: o gay e o cervo. Viado é assim o erro que define/constrói uma categoria de humanos específica, $a b$ ovo já errados, nãonaturais, ilegítimos.Mas o nome de veado não desaparece, ele vigora ainda a designar o animal. Então, no viado há essa dupla filiação: o erro e o bicho. O bicho (como bicha) está na vontade de tornar animal - leia-se: menos humanas - essas pessoas des-viadas.

\section{Quando o nome veado vem a ser viado?} Quando se usa veado para ofender as pessoas? e depois, quando se escreve esse nome com i para não haver dúvida do que se está falando? Há um movimento no tempo e no espaço aí neste i que é diferença/différance. Esse erro ortográfico tem sua própria história de repressão.

7. Viado: de veado, de desvio, de erro, de animal. De que mais? Um veado é um viado é um viado é um viado. A polissemia da vogal abre toda a história de um nome para seus usos possíveis, seus significados em ação, os afetos mobilizados.
Numa conceitualidade clássica e respondendo a exigências clássicas, diríamos que "diferança" [différance] designa a causalidade constituinte, produtora e originária, o processo de cisão e de divisão do qual os diferentes ou as diferenças seriam os produtos ou os efeitos constituídos. (DERRIDA, 1991, p. 39).

Não é suficiente declarar que os sujeitos humanos são construídos, pois a construção do humano é uma operação diferencial que produz o mais ou menos "humano", o inumano, o humanamente impensável. Esses lugares excluídos vêm para limitar o "humano" em seu exterior constitutivo, e para provocar essas fronteiras como possibilidades persistentes de disrupção e rearticulação. (BUTLER, 1993, p. xvii).

A diferança [différance] é o que faz com que o movimento de significação não seja possível a não ser que cada elemento dito "presente", que aparece sobre a cena da presença, se relacione com outra coisa que não ele mesmo, guardando em si a marca do elemento passado e deixando-se já moldar pela marca da sua relação com o elemento futuro, relacionandose o rastro menos com aquilo que se chama presente do que àquilo a que chama passado, $\mathrm{e}$ constituindo aquilo a que chamamos presente por intermédio dessa relação mesma com o que não é ele próprio: absolutamente não ele próprio, ou seja, nem mesmo um passado ou um futuro como presentes modificados. (DERRIDA, 1991, p. 45). 
8. Viado é um insulto, o mais comum usado neste país. Viado também é uma forma familiar, carinhosa, identitária, amistosa usada pelos viados, isto é: homens homossexuais, entre si e com outras pessoas. De uma palavra não se espere fidelidade: ela rompe os cercos para se dar à violação de qualquer um. Essa disponibilidade provocativa da língua é nosso maior bem. Viado, como ofensa e como estima, é usado indiscriminadamente entre os falantes da língua brasileira.

9. A repressão na origem - insultar uma pessoa - não se perde. Faz parte do jogo transgredir a ofensa para jamais se fazer esquecer que ela perde sua força de injúria agora nesse contexto determinado. Cita-se, portanto. E toda citação pode ser enxertada em outro contexto, gerando por sua vez novos contextos.

10. O discurso de ódio usado pelo oprimido não desaloja o ódio. Ele permanece como traço diferencial do próprio signo. Da parte do jogo de oposições que define o signo saussureano, o traço de um uso fóbico não é apagado, logo ignorado, quando se reverte esse uso seja via politização, derrisão ou subversão. Toda forma de deslocamento de sentido no discurso de ódio vai reiterá-lo, porque é da ordem da linguagem a própria iteração. Cada iteração, em variado contexto, modifica o discurso de ódio. Porque a língua permite ser citada de uma maneira não-saturável, existe sempre no horizonte a possibilidade do indizível deixar de sê-lo. Enquanto viado pode ser usado por qualquer um, em contextos não necessariamente fóbicos, nem todo discurso de ódio possui neste momento histórico de apropriação igual.
Paradoxalmente, é a insistência paranoica com que as barreiras entre "os homossexuais" (minoria) e "os heterossexuais" (maioria) são reforçadas, neste século [XX], por nãohomossexuais e, especialmente, por homens contra homens, que mais abala a capacidade de acreditar no "homossexual" como uma categoria distinta e não problemática de pessoas. (SEDGWICK, 2008, p. 83-4).

[Homofobia] é a discriminação para com as pessoas que mostram, ou a quem se emprestam, certas qualidades (ou defeitos) atribuídos ao outro gênero. (WELZERLANG, 2004, p. 118). 
11. Queer é um nome da língua inglesa que também é um insulto ressignificado. Mas queer nunca possuiu essa história de erro e desvio que o nome viado possui. Queer sempre foi estranho/ esquisito e continua a ser (apesar do uso político mais conotado atualmente). Viado não perdeu o sentido de insulto nem o posto de maior ofensa atribuída a um homem. Queer não é o palavrão de escolha para insultar alguém como viado ainda é. Essa diferença só engendra polissemia em nossa língua, portanto em nossa própria cultura. Nós precisamos nos haver com o fato de nossa sociedade reservar a algumas pessoas uma ontologia do menosprezo baseada na injúria, no erro, no desvio e na desumanização.

12. Queer é um adjetivo, cujo substantivo é queerness. O sufixo -ness é uma forma comum da língua inglesa para substantivar adjetivos. Viado, embora predicado, não é da mesma categoria até quando usado para qualificar: a mulher viada, a teoria viada, o livro viado, o amor viado. O estranhamento revela o uso esporádico. Enquanto nome, viado impera. De viado vem viadagem. O sufixo nominal -agem geralmente indica a substantivação de verbos em português, e serve para indicar o resultado ou o processo de uma ação: do ato de aprender, aprendizagem; do de vadiar, vadiagem, etc. Viadagem, apesar de não originar diretamente de verbo, é aquilo que os viados fazem. É a ação de um viado no mundo. O poder nomeador que institui um sujeito, chamado de viado, precisa informar sobre os vestígios desse sujeito ao longo da história. Esse vestígio, essa marca, se chama viadagem.
Queerness não existe no sistema semântico e conceitual da falocracia e, por exatamente essa razão, os sujeitos queer "gozam uma certa flexibilidade e liberdade dos limites [e proibições] impostas por tal sistema". (SANTOS, 2002, p. 21). 
13. A viadagem não nega a origem homofóbica e por isso seu uso também é derrogatório. Tal como o viado, viadagem reside na encruzilhada dos usos que se fazem dela na língua. A força mercurial dessas palavras provê uma ferramenta interessante de desconstrução.

14. Viadagem é uma estrutura masculina. Viados: diz-se de homens, não de mulheres. Viadagem é a prática do viado, a repetição dos atos conformadores de uma identidade fixada como gay na cultura e na linguagem. Viadagem não é devir, pelo contrário, sua função é erguer um centro organizador da homossexualidade masculina, surpreendida como essência reveladora de uma peculiar sensibilidade. Este uso particular autoriza o uso da noção para desqualificar atitudes de efeminação. Nós podemos, como o vírus, usar isso ao nosso favor.

15. Como um vírus, isto é, replicando com uma diferença letal para dominar o sistema. Apenas homens podem ser viados, portanto a viadagem nos informa sobre um limite da masculinidade na efeminação. Homens hétero entendem viadagem como diminuição de atributos masculinos, percebida em práticas não normativas de homens gays. Quando essas práticas são assimiladas pela heteronormatividade, deixam de ser viadagem. O sistema é permeável desse jeito porque o homem homossexual não abdica do privilégio masculino. A homossexualidade masculina não ameaça o patriarcado quando joga nos mesmos termos, reproduzindo misoginia e falocentrismo. É importante definir a viadagem como mais uma estrutura que exclui as mulheres como participantes ativas do processo, porque assim nós poderemos erodir os privilégios da masculinidade às quais todos nós lançamos mão. A estratégia do vírus é a do romance de
Podemos ir além disso, dizer que em qualquer sociedade dominada pelo masculino há uma relação especial entre o desejo homossocial de homens (incluindo o desejo homossexual) e as estruturas mantenedoras e transmissoras do poder patriarcal: uma relação fundada numa inerente e potencialmente ativa congruência estrutural. Por razões históricas, essa relação especial pode tomar a forma de homofobia ideológica, homossexualidade ideológica ou uma combinação altamente conflitante mas intensamente estruturada de ambas. (SEDGWICK, 1985, p. 25).

Esta metáfora me foi sugerida pela letra da canção "Virus", de Björk: The perfect match, you and me/ I adapt, contagious/ You open up, say welcome/ (...) My sweet adversary.

Em seus desejos, o homem gay corre o risco de se identificar com imagens culturalmente dominantes da virilidade misógina. Uma afinidade mais ou menos secreta com a misoginia masculina heterossexual carrega em si a recompensa narcisisticamente gratificante de confirmar nossa associação na (e não simplesmente nosso apetite erótico pela) sociedade masculina privilegiada. (BERSANI, 2010, p. 42). 
amor trágico. Uma história de amor onde os amantes morrem. O vírus precisa do organismo para se reproduzir, criar descendência e se disseminar, e será bem sucedido em suas intenções somente quando o organismo do qual necessita para viver morre. A morte dá sentido à vida de um vírus - ele criou posteridade. Como o vírus, a viadagem pode reprogramar um sistema geralmente desatento com as normas privilegiadas que o constitui para arruiná-las.

16. A misoginia é uma potência de opressão para reforço da masculinidade hegemônica, disponível para homens não-hétero e também para mulheres. Nossa sociedade se edifica tendo em uma de suas bases a repressão do feminino. A feminilidade como força de desconstrução, e não como essência, é que foi preciso neutralizar historicamente, não a homossexualidade. Enquanto as pessoas homossexuais sofrem diversas formas de opressão e falta de direitos civis, o sexo e o afeto entre homens mobiliza um imaginário importante para a sensibilidade ocidental. A existência desses lugares onde homens se encontram para sexo anônimo não são apenas a prova da fluidez das identidades, mas das técnicas de preservação da masculinidade. Não existem saunas, cinemas pornôs e cabines de sexo exclusivas para mulheres. O segredo público desses espaços tem a razão de ser como uns dos poucos lugares onde a norma hétero se revela tão arbitrária ou construída quanto aquelas que ela visa reprimir. E como na viadagem, as mulheres são excluídas.

17. A viadagem, que também é celebração, afetividade, sensibilidade, coloca a hegemonia masculina no interior de uma potência de desconstrução operada pela feminilidade. Também chamamos de viadagem o processo naturalizado dessa desconstrução.
Ocorposugeremortalidade, vulnerabilidade, agência: a pele e a carne nos expõem ao olhar dos outros mas também ao toque e à violência. $\mathrm{O}$ corpo pode ser agência $\mathrm{e}$ instrumento deles também, ou o lugar onde "fazer" e "ser feito" se torna impreciso. Apesar de lutarmos por direitos sobre nossos corpos, os próprios corpos pelos quais lutamos não são totalmente apenas nossos. O corpo tem uma dimensão pública invariável; constituído como fenômeno social na esfera pública, meu corpo é e não é meu. (BUTLER, 2004, p. 21). 
18. Questões sob siglas LGBT e GLS ainda são todas centradas a partir da norma hétero. Seja lutando por legitimidade, seja buscando assimilação ou questionando a hegemonia, o debate se desenvolve tendo por horizonte uma alternativa à heterossexualidade. Propor o feminino como alternativa pode nos levar até o neutro mulher-branca-heterossexual como contraste à sua versão masculina. Criar centros não me parece a opção mais interessante. $\mathrm{O}$ centro supõe a precedência de um princípio organizador de toda reflexão. $\mathrm{O}$ pensamento periférico, por outro lado, permite transversalidades e simultaneidades mais prolíficas.

19. A viadagem é da ordem do pensamento bastardo porque não esconde a erosão de suas paredes. Ela autoriza o escrutínio de uma edificação de outra maneira ocultada por andaimes e tapumes. A viadagem desmorona uma estruturação homossocial. A viadagem enfatiza a estrutura masculina da homossexualidade. Ninguém está livre de reproduzir o discurso de ódio e a prática da repressão. Um pensamento transversal de viadagem evidencia uma das violências necessárias para se sustentar o Ocidente - o nome dela é misoginia.

20. A contribuição da viadagem para a teoria de gênero: o privilégio masculino é uma modalidade de poder exercido na e através da neutralização dos pactos sociais, convenções culturais, controle do imaginário, demarcações e regimes de ethos para que a dominação masculina receba o nome de neutro. A viadagem desconstrói na medida em que ela mesma é o resultado da força feminina agindo sobre a masculinidade. Por isso as mulheres, apesar de excluídas da viadagem, não deixam de comparecer nesse jogo. 
21. Viadagem não é um conceito nem poderia vir a sê-lo. É uma prática, e uma forma coercitiva de prática da identidade. Por isso a necessidade de usá-la a nosso favor. Onde a viadagem reside como produção do poder sobre a política identitária, reside também a chance de questionála naquilo que ela naturaliza: a efeminação como rasura da masculinidade rasura também o modelo hegemônico de normatividade hétero.

22. A viadagem é um método de leitura, ou, antes, deumaleitura a contrapelo. Nossas interpretações viciadas e cegadas pela neutralização do neutro são desveladas pela efeminação da viadagem. Efeminação: maneirismo, afetação, diminuição da masculinidade. Porque é fundamental pensar o masculino em favor de uma equação paritária. Se nos querem tão viados, tão viados quanto totens, usemos o mesmo artifício a nosso favor, mas para apontar na normatividade sua constituição igualmente arbitrária.

23. A viadagem, masculina em si, é de segunda mão. Depois de passar pelas instâncias coercitivas, que designam um viado, ela é recebida por eles e reivindicada. O grande perigo: estamos acostumados demais a ser homens, seguros demais da alteridade que nos foi imposta ao ponto de protagonizarmos por tanto tempo no gueto da identidade as lutas políticas. Sob o nome de viado também se suprime as complexas intersecções entre sexualidade e classe, origem, geração e etnia, constituindo uma entidade não-problemática. Somos o status quo da marginália sexual. 
24. Ainda somos bastardos o suficiente? Estamos, à maneira dos peixes, muito convictos do meio que nos rodeia para não conseguir identificar, nós mesmos, os nossos privilégios? Não precisamos, nós, homens gays, de mais viadagem para perceber quando o desvio se torna autoestrada? 


\section{Referências}

BERSANI, Leo. Is the rectum a grave? Chicago: Chicago University Press, 2010.

BUTLER, Judith. Bodies that matter: on the discursive limits of "sex". New York: Routledge, 1993.

BUTLER, Judith. Excitable speech. New York, Routledge, 1997.

BUTLER, Judith. Undoing Gender. New York: Routledge, 2004.

BUTLER, Judith. Problemas de gênero: feminismo e subversão da identidade. $3^{\text {a }}$ ed. Rio de Janeiro: Civilização Brasileira, 2010.

DERRIDA, Jacques. Limited Inc. Tradução de Constança Marcondes Cesar. Campinas: Papirus, 1991a.

DERRIDA, Jacques. Margens da filosofia. Campinas: Papirus, 1991.

SANTOS, Rick. "Dessencializando queerness à procura de um corpo (textual) queer inclusivo". In: SANTOS, R.; GARCIA, Wilton (Org.). A escrita de adé. São Paulo: Xamã, NCC/SUNY, 2002, p. 15-22.

SEDGWICK, Eve Kosofsky. Between men: English literature and male homosocial desire. New York: Columbia University Press, 1985.

SEDGWICK, Eve Kosofsky. Epistemology of the closet. California: University of California Press, 2008.

WELZER-LANG, Daniel. “Os homens e o masculino numa perspectiva de relações sociais de sexo” . In: SCHPUN, M. R. (Ed.). Masculinidades. São Paulo: Boitempo Editorial, 2004. p.107128. 